\title{
A Hazard-Free Framework for Aerial Distribution of Pesticides on Agricultural Land
}

\author{
Hazrat Ali ${ }^{1 a}$, Ali Zahir ${ }^{1 b}$, Shahid Khan ${ }^{2}$, Naseer Ahmad ${ }^{3}$, Ahmad Fayyaz $^{1 \mathrm{c}}$
}

RECEIVED ON 12.11.2018, ACCEPTED ON 26.07.2019

\begin{abstract}
Pesticide spray is essential for pest control, crop production and protection. However, the direct contact of these pesticides with humans may cause cancer, complication in the respiratory system and neurological disorders. This problem is more severe in developing countries as each year more than 100 thousand death cases are reported by World Health Organization. This work presents a modification approach of Quadcopter into a UAV, in such a way that it can fly in manual as well as autopilot mode and can spray on agricultural lands using its ground control station. In this work, a stable system is developed for aerial distribution of pesticides as well as fertilizer to reduce human contact with pesticides. The system consists of; a) a remotecontrolled UAV (Unmanned Aerial Vehicle) which is controlled from ground through a flight controller and b) a spraying system which is manually triggered by RF controlled circuit. The reliability of the proposed framework is evaluated on a test area of around $1000 \mathrm{~m}^{2}$. The pumping rate of sprayer system is adjusted to 40 $\mathrm{mL} / \mathrm{min}$ with PWM at $45 \%$ duty cycle. From results it can be concluded that the integration of UAV with the spray system results in a spraying mechanism which is very efficient and hazard-free for crop pest management in the small field area.
\end{abstract}

Keywords: Quadcopter, Autopilot, Agricultural Applications, Aerial Distribution.

\section{INTRODUCTION}

$\mathrm{M}$ odern technology is benefiting us in many ways. Dependency on scientific means to get quality product on economical prices has been increased. Like many other fields, agriculture is also adapting modern means of technology to increase its productivity with minimum financial resources. One of the major factors that increases the agricultural product is the timely and accurate distribution of the pesticides. Many technological developed countries have already adopted different means to efficiently utilize pesticides on different corps and trees. Pakistan which is an agricultural country highly needs to adopt modern mechanisms and replace conventional mechanism of farming with modern technology. Previously very few mechanisms were owned to spray pesticides more accurately with fewer losses. In this work, a framework based on quadcopter is used to distribute pesticides on the crop by knowing the coordinates of a given field. The purpose of this prototype demo was to compare the accuracy of the pesticides distribution with conventional mechanisms and conclude the financial differences in both the processes.

In a quadcopter, two of the rotors turn clockwise, while the other two turn counter clockwise to provide

${ }^{1}$ Department of Electrical and Computer Engineering, COMSATS University Islamabad, Abbottabad Campus, Abbottabad, Pakistan. Email: ahazratali@cuiatd.edu.pk, balizahir@cuiatd.edu.pk (Corresponding Author), cafayyaz@cuiatd.edu.pk

${ }^{2}$ LCOMS, ASEC, University of Lorraine, Metz, France. Email: shahid.khan@univ-lorraine.fr

${ }^{3}$ Faculty of Information and Communication Technology, Balochistan University of Information Technology, Engineering and Management Sciences, Quetta, Pakistan. Email: naseer.ahmad @ buitms.edu.pk

This is an open access article published by Mehran University of Engineering and Technology, Jamshoro under CC BY 4.0 International License. 
a stable hovering. The takeoff and hovering can be used for multiple functions like photography, video monitoring etc. Here, we are modifying the quadcopter into an unmanned praying machine for the purpose of pesticides distribution on agricultural land [1-3]. Prolong contact of humans with these pesticides directly or indirectly, can cause various diseases to humans such as cancer, complication in the respiratory system and neurological disease [1-3]. The World Health Organization (WHO) estimates that there are more than 1 million pesticide related patients' cases every year. In these, more than 100 thousand deaths occur each year, especially in developing countries due to the pesticides being sprayed by humans [4-5].

Pesticides distribution through agricultural drone is very useful because of the following reasons: (i) To reduce human contact with chemicals which ensure human health safety and (ii) to enhance spraying mechanism performance by providing a controlled and uniform spraying machine. Agricultural drones have the potential to improve the crops production and save human health from hazardous chemicals present in pesticides [5-8]. Typically, the controlling of agricultural drones is hard as there are multiple algorithms and sensors to calibrate but this problem is solved after the invention of ArduPilot (APM) which itself is a complete form of all the controlling and balancing components; it has a built in ports for compass and GPS which are very easy to be calibrated. The sensors and calibration components of APM 2.6 makes the handling easier. This method can be useful in different conditions especially in areas where we have shortage of man force. It also makes the environment pollution free by spraying from low altitude.

The main purpose of this work is to provide a stable system for aerial distribution of pesticides. After going through literature review and checking different electronics equipments we found the APM as a stable and easily operating controller which has built in calibration components like compass and accelerometer. For the spraying mechanism, we have designed a controlling circuit which controls the spraying by taking input from the APM and keeping the weight within specific limits.

\section{PROPOSED MODEL}

The proposed work presents the modification of a quadcopter into an aerial spraying machine. For this project a quadcopter having four equally spaced rotors and symmetrically pitched blades is selected. Unlike four-channel helicopter, the multi-rotor flying machine provides different number of controllable functions [9-12]. The counter clock-wise (CCW) and Clock-wise (CW) motion of two paired synchronous motors create a downward thrust for the lifting of quadcopter. By varying the speed of these motors, various movements can be achieved. The four important terms, used for the movement of multicopter are; a) YAW (Rudder), b) ROLL (Aileron), c) PITCH (Elevators) and d) throttle (vertical translation) which provide the flexibility for the quadcopter movement in any direction.

Radio flight controller (RFC) is used to control the movement of the flying machine. The function of the RFC is to evaluate the RPM signal for each rotor according to the input from the base or ground station and controls the movement of quadcopter accordingly. In addition to flight movements, a separate spraying system is installed which is controlled by RF signals. Therefore, for controlling movements of flying machine and spraying system, a six channel quadcopter is used.

The detail of the quadcopter, flight controller and spraying system used in our model is given in the following subsections.

\subsection{F450 Quadcopter}

F450 quad copter is a multi-rotor designed to achieve different movements including hovering, cruising, and rolling. It consists of the following modules; (a) top/bottom boards and frame arms, (b) Multicopter specialist Brushless DC motors (BLDC) and (c) specially designed multi-rotor Electronic Speed Controllers (ESCs). The top board is made up of Toray $3 \mathrm{~K}$ carbon fiber cloth which is very strong and light in weight. The bottom board uses a high strength of PCB material to make the wiring of controllers easier and safe on the lower one of the two frame boards. The overall frame design provides enough 
space for assembling the auto-pilot system between the top and the bottom boards of the quad copter. This frame can stand well to a medium payload, such as a small pesticide tank, or a single camera.

\subsection{Flight Controller}

The flight controller of quadcopter consists of two components; (a) 7 channel Radio Control (RC) receiver, R617FS and (b) ArduPilot Mega (APM) 2.6 autopilot system (see Fig. 1). AMP 2.6 is placed between the receiver and multicopter rotors by connecting the receiver to the APM's input ports while the motors and the servo are connected to the output ports of the APM. The direct connection of receivers and motors are bypassed through APM board. The orientation of the APM is an important factor and placing it in the wrong direction may lead to malfunction of the quadcopter. Fig. 1 shows block diagram of the connection of pilot controller APM 2.6 and other quadcopter components. APM is actually the brain in this flying machine, which monitors operations and autonomous navigation of the drone system. All the components in a multicopter are connected with APM. It helps the copter to synchronize all its components and control them accordingly. APM can be connected to the ground control through which commands are fed as per our need. Moreover, any trajectory or mission plan can be directly uploaded to the APM so that it is followed through ground control.

\subsection{Spraying System}

A spraying system was designed and installed on the UAV. The spraying system consisted of four key components: a) main controlling circuit for precise spray activation, b) tank to hold pesticide material, c) a gear pump and d) mounted spray nozzle. Fig. 2 shows the spraying controlling mechanism of the spraying system. The RF receiver acts as auxiliary communication system to the spraying controlling circuit to the flight controller. A command signal from the flight controller is fed to the controller circuit via APM, which then connects $12 \mathrm{~V}$ battery to water gear pump. Depending upon the PWM signal from the control circuit, the pump starts supplying pesticide to the spraying nozzle with specific amount which is then expelled out.

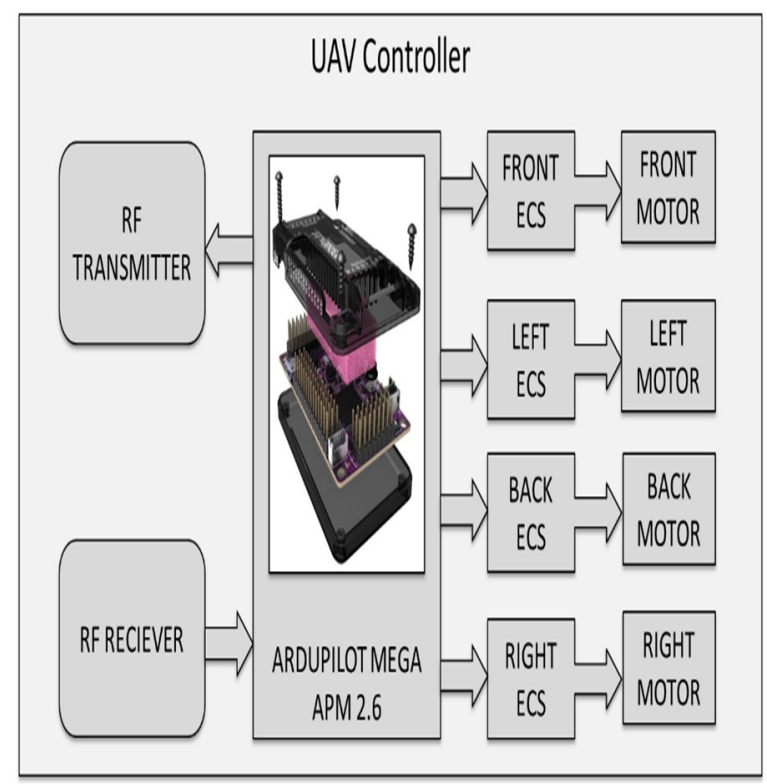

FIG. 1: FLIGHT CONTROL CHART

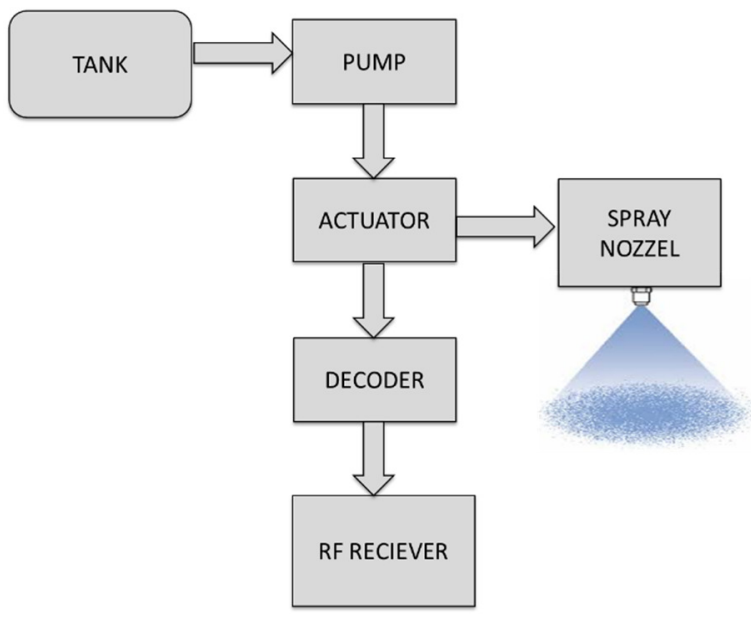

FIG. 2: SPRAYING CONTROL SYSTEM STRUCTURE

\section{CONTROLLING CIRCUIT}

The main spraying controlling circuit includes a High Voltage High Current relay interface IC ULN2003, a $5 \mathrm{~V}-12 \mathrm{~V}$ DC relay and a $12 \mathrm{~V}$ DC motor. As the motor initially draws more current which can damage the associated circuitry having low current ratings, therefore, a circuit is designed for the protection of the associated circuitry. Fig. 3 shows the control circuit for the spraying mechanism. Output signal from pin number A9 of APM is connected to the input of ULN2003. As the output signal from APM is very low 
to energize the relay directly, therefore, ULN2003 is used to interface $5 \mathrm{~V}$ relay to the APM board. When the relay is energized, it connects the $12 \mathrm{~V}$ battery to liquid pump. In the experiment, we also used water tank and water pump as shown in Fig. 4. The water tank is a mini tank with the capacity of $180 \mathrm{ml}$. Weight of tank is up to 30 grams and the liquid pump was also fitted in here. Liquid pump (detailed description in Table 1) is a small dc $12 \mathrm{~V}$ submersible water pump. The detail of complete UAV with spraying mechanism is shown in Fig. 5.

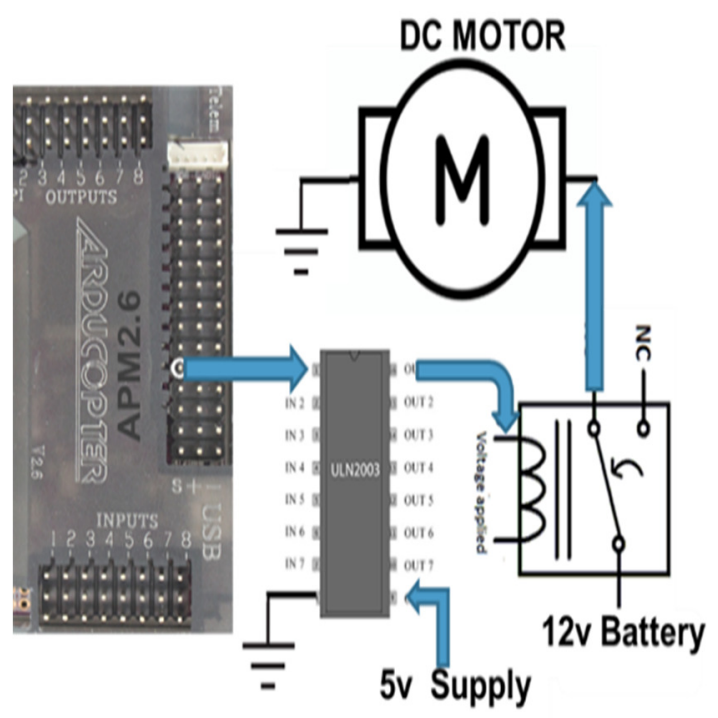

FIG. 3: CONTROL CIRCUIT FOR THE SPRAYING MECHANISM

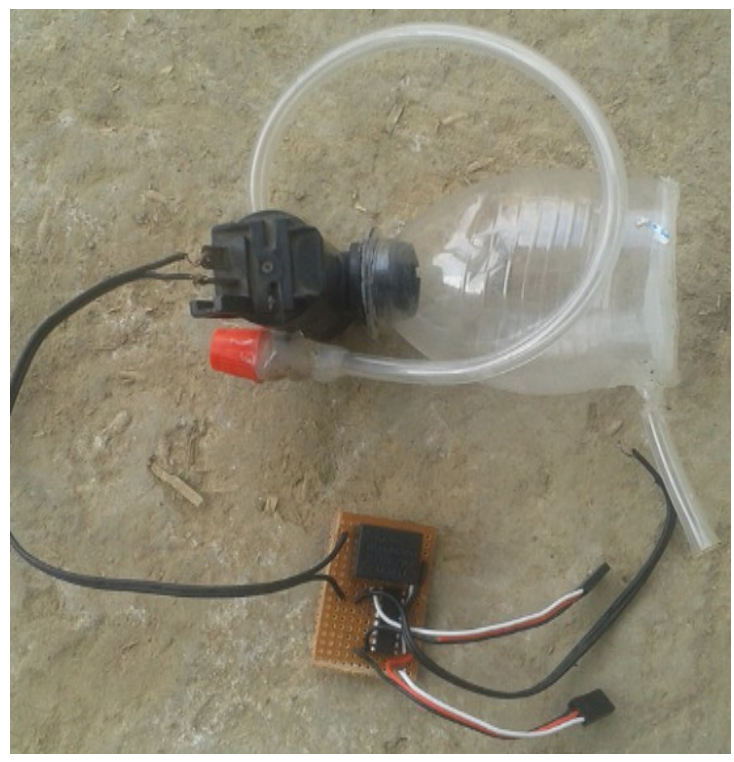

FIG. 4: PROVIDE DETAIL OF CONTROLLING CIRCUIT WITH SPRAYING TANK

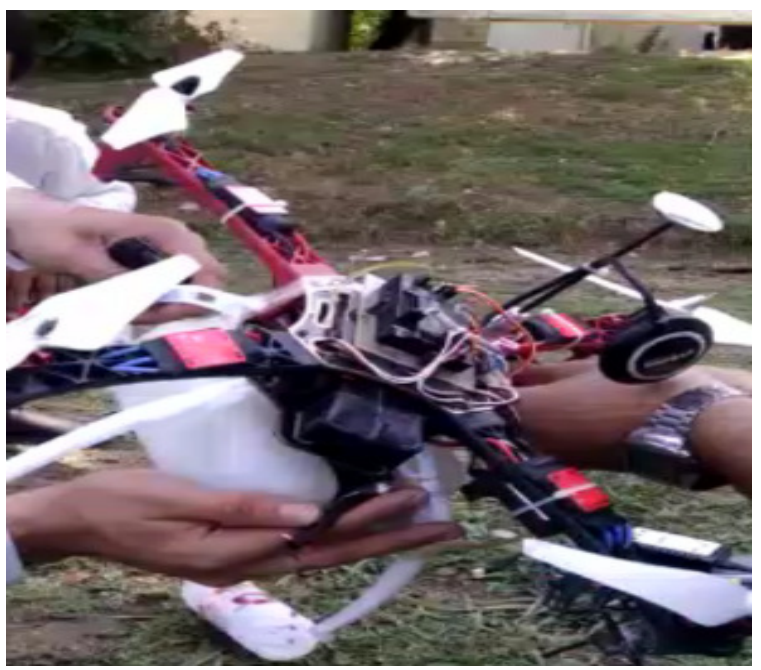

FIG. 5: INTEGRATED UAV SYSTEM WITH SPRAYING MECHANISM

\begin{tabular}{|c|c|c|}
\hline \multicolumn{3}{|c|}{$\begin{array}{l}\text { TABLE 1: PARAMETER OF SPRAYING CONTROLLING } \\
\text { SYSTEM }\end{array}$} \\
\hline Items & & Parameters \\
\hline Size (mm) & $\begin{array}{c}\text { Height } \\
\times \text { diameter }\end{array}$ & $98 \times 38$ \\
\hline Weight (g) & & 100 \\
\hline \multirow{2}{*}{$\begin{array}{l}\text { Water outlet } \\
\qquad(\mathrm{mm})\end{array}$} & $\begin{array}{c}\text { Outer } \\
\text { diameter }\end{array}$ & 12 \\
\hline & Inner diameter & 9.7 \\
\hline $\begin{array}{l}\text { Supply Voltage } \\
\text { (V) }\end{array}$ & & 12 \\
\hline \multirow{2}{*}{$\begin{array}{l}\text { Output (liquid } \\
\text { pump) }\end{array}$} & $\begin{array}{c}\text { Working } \\
\text { voltage }(\mathrm{V})\end{array}$ & $6-15$ \\
\hline & $\begin{array}{l}\text { Rated current } \\
\text { (A) }\end{array}$ & 1.2 \\
\hline $\begin{array}{c}\text { Flow Rate } \\
\text { (L/Hour) }\end{array}$ & & $\begin{array}{c}840 \\
\text { (Maximum) }\end{array}$ \\
\hline $\begin{array}{l}\text { Maximum Lift } \\
(\mathrm{m})\end{array}$ & & $5(\mathrm{~m})$ \\
\hline
\end{tabular}

\section{EXPERIMENTS AND RESULTS}

In order to confirm the reliability of the system, the test area of around $1000 \mathrm{~m}^{2}$ was selected. It was an open area where the route was $20 \mathrm{~m}$ wide and the length was $50 \mathrm{~m}$. Based on the initial tests, the UAV was first taken to the altitude of $5 \mathrm{~m}$ and then it was brought down to $3-4 \mathrm{~m}$ for spraying purpose. The UAV is controlled from the ground through a flight controller where a dedicated switch was assigned to perform the spraying task. All other operations such as flying speed, moving and changing direction were controlled by radio controlled flight controller. The payload for the spraying system of our design was 
400grams, so we limited our spraying content to $200 \mathrm{ml}$. The flying view of UAV is shown in Fig 6.

Time selected for spraying was 10:00 am. This is suitable for time spraying because the dew factor is minimum at this time in most regions of the Khyber Pakhtunkhwa province.

The flight time of UAV depends on the battery capacity. A $198 \mathrm{~g}$ three cells lithium polymer battery with a capacity of $2200 \mathrm{mAH}$ and a discharge rate of $25 \mathrm{C}$ was used in this project. The output voltage of the battery is $12 \mathrm{~V}$, which is according to our system requirement. Besides the battery capacity, another parameter which affects the flight time is the payload of the system. The detail of the payloads of our system is given in Table 2. The weight of nozzle, tubes, spraying control circuit and water tanks reduces the net payload of the UAV. The allowed payload for the spraying system was 400grams. Exceeding the payload limit may heat up the battery which can cause the fast battery discharge and thus lowers the flight time. For this reason the spraying content was limited to $200 \mathrm{ml}$. The specific gravity of the chemical used as spraying content is $0.86 \mathrm{~kg} / \mathrm{L}$, which resulted in $174 \mathrm{~g}$ of payload for $200 \mathrm{ml}$ chemical contents.

\begin{tabular}{|c|c|}
\hline \multicolumn{2}{|c|}{$\begin{array}{l}\text { TABLE 2: PAYLOADS DETAIL OF UAV SPRAYING } \\
\text { SYSTEM }\end{array}$} \\
\hline Items & Weight $(\mathrm{g})$ \\
\hline Tubes plus nozzle & 40 \\
\hline Motor & 100 \\
\hline Control circuit & 50 \\
\hline $\begin{array}{l}\text { Water tank plus chemical } \\
\text { (maximum) }\end{array}$ & $184 \pm 6$ \\
\hline Total & 374 \\
\hline
\end{tabular}

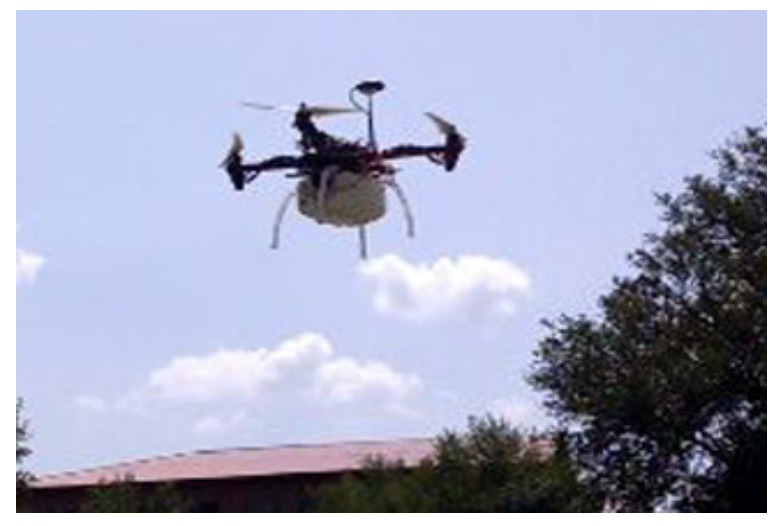

FIG. 6: FLYING VIEW OF THE UAV SYSTEM
Fig 7 shows the estimated flight time as a function of payload of the spraying content. In first case, the spraying system is not attached to the system. The flight time shows a highly linear dependence on payload $\left(\mathrm{R}^{2}=0.9849\right)$. The maximum flight time with no extra load is around 11 minutes. While with full payload, the minimum flight time is around 6.5 minutes. In second case, the spraying system is attached and remains active. In order to cover the test area of $1000 \mathrm{~m}^{2}$, the pumping rate of the sprayer needs about the $40 \mathrm{~mL} / \mathrm{min}$. This could be achieved by adjusting PWM at $45 \%$ duty cycle, which produces an average $5.7 \mathrm{~V}$. The flight time of UAV with active spraying system also shows linear dependence on payload with $R^{2}=0.9784$. The average flight time of UAV with spraying system is lower than the UAV without spraying system. Initially when the payload due to spraying content is zero, the difference is 1.5 minutes. However at $400 \mathrm{~g}$ payload, the difference is reduced to 0.3 minutes. In second case, the spraying content was reduced at rate of $40 \mathrm{~mL} / \mathrm{Min}$, thus the weight is reduced overtime.

\section{-Flight time W/O sprying system \\ - Flight time W Spraying system \\ __ Linear (Flight time W/O sprying system) \\ _L Linear (Flight time W Spraying system)}

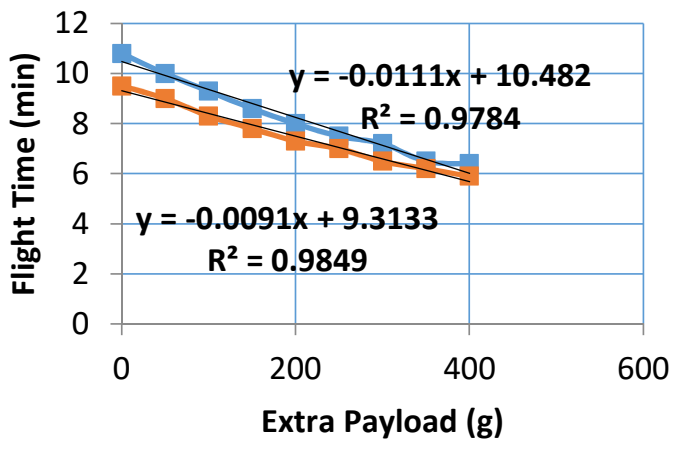

FIG.7: FLIGHT TIME AS A FUNCTION OF PAYLOAD FOR UAV WITHOUT SPRAYING SYSTEM AND WITH ACTIVE SPRAYING SYSTEM.

\section{CONCLUSION}

In this work, a precise mechanism for aerial spraying by modifying a quadcopter has been presented. After practical demonstration, it can be concluded that the use of APM makes it easy to handle the operations in

Mehran University Research Journal of Engineering and Technology, Vol. 39, No. 3, July 2020 [p-ISSN: 0254-7821, e-ISSN: 2413-7219] 
light breeze because of its built-in compass and accelerometer which calibrates itself according to the environment. The integration of UAV with the spray system results in a spraying mechanism which is efficient and hazard-free for both humans and crops. It gives a uniform and risk free spraying mechanism covering field area in lesser time compared to humans. The flight time of UAV shows linear dependence on payload with $\mathrm{R}^{2}=0.9784$. If we could increase the payload of the quadcopter to carry some more weight, a solar panel can be linked to the system to recharge the battery and to cover the larger area.

\section{REFERENCES}

[1] Mostafalou, S., and Abdollahi M.. "Pesticides and human chronic diseases: evidences, mechanisms, and perspectives." Toxicology and Applied Pharmacology, Vol. 268, No. 2, pp. 157-177, 2013.

[2] Mostafalou, S., and Abdollahi M., "Pesticides: an update of human exposure and toxicity." Archives of Toxicology, Vol. 91, No. 2, pp. 549-599. 2017.

[3] Giovenale G., Zugna D., Grasso C., Mirabelli D., Lista P., Ciuffreda L., Segnan N., Merletti F., and Richiardi L., "Postnatal risk factors for testicular cancer: The Epsam case-control study." International Journal of Cancer, Vol. 141, No. 9, pp. 1803-1810, 2017.

[4] Emma E.J., Padmanathan P., Konradsen F., Eddleston M., Chang S-S, Phillips M.R., and Gunnell D., "The global burden of fatal selfpoisoning with pesticides 2006-15: systematic review", Journal of Affective Disorders, Vol. 219, pp. 93-104, 2017.

[5] Engel, L.S., Werder E., Satagopan J., Blair A., Hoppin J.A., Koutros S., Lerro C.C., Sandler D.P., Alavanja M.C., and Freeman L.E.B., "Insecticide Use and Breast Cancer Risk among Farmers' Wives in the Agricultural Health Study." Environmental Health Perspectives, Vol. 125, No. 9, 2017.
[6] Faiçal B.S., Costa F.G., Pessin G., Ueyama J., Freitas H., Colombo A., Fini P.H., Villas L., Osorio F.S., Vargas P.A., Braun T., "The use of unmanned aerial vehicles and wireless sensor networks for spraying pesticides", Journal of Systems Architecture, Vol. 60, No. 4, pp. 393-404, 2014.

[7] Aha D.W., Kibler D., and Albert M.K.. "Instance-based learning lgorithms", Machine Learning, Vol. 6, No. 1 pp. 37-66, 1991.

[8] Torres-Sánchez, j., López-Granados F., and Peña J.M., "An automatic object-based method for optimal thresholding in UAV images: Application for vegetation detection in herbaceous crops", Computers and Electronics in Agriculture, Vol. 114, pp. 4352, 2015.

[9] Angelov, P., Filev D.P., and Kasabov N., Eds. Evolving Intelligent Systems: Methodology and Applications, John Wiley \& Sons, 2010.

[10] Pérez-Ortiz, M., Peña J.M., Gutiérrez P.A., Torres-Sánchez J., Hervás-Martínez C., and López-Granados F., "Selecting patterns and features for between-and within-crop-row weed mapping using UAV-imagery", Expert Systems with Applications, Vol. 47, pp. 8594, 2016.

[11] Akyildi I.F., and Vuran M.C., Wireless Sensor Networks, Vol. 4, John Wiley \& Sons, 2010.

[12] Tokekar, P., Hook J.V., Mulla D., and Isler V., "Sensor planning for a symbiotic UAV and UGV system for precision agriculture." IEEE Transactions on Robotics, Vol. 32, No. 6, pp. 1498-1511, 2016. 